\section{Genetic and phenotypic characterization of indolent T-cell lymphoproliferative disorders of the gastrointestinal tract}

\author{
Craig R. Soderquist, ${ }^{1}$ Nupam Patel, ${ }^{1}$ Vundavalli V. Murty, ${ }^{1}$ Shane Betman, ${ }^{1}$ \\ Nidhi Aggarwal, ${ }^{2}$ Ken H. Young, ${ }^{3}$ Luc Xerri, ${ }^{4}$ Rebecca Leeman-Neill, ${ }^{1}$ Suzanne \\ K. Lewis, ${ }^{5}$ Peter H. Green, ${ }^{5}$ Susan Hsiao, ${ }^{1}$ Mahesh M. Mansukhani, ${ }^{1}$ Eric D. \\ Hsi, ${ }^{6}$ Laurence de Leval, ${ }^{7}$ Bachir Alobeid ${ }^{1}$ and Govind Bhagat ${ }^{1}$ \\ ${ }^{1}$ Department of Pathology and Cell Biology, Columbia University Irving Medical Center, \\ New York Presbyterian Hospital, New York, NY, USA; ${ }^{2}$ Department of Pathology, University \\ of Pittsburgh Medical Center, Pittsburgh, PA, USA; ${ }^{3}$ Department of Hematopathology, MD \\ Anderson Cancer Center, Houston, TX, USA; ${ }^{4}$ Department of Bio-Pathology, Institut Paoli- \\ Calmettes, Aix-Marseille University, Marseille, France; ${ }^{5}$ Department of Medicine, Celiac \\ Disease Center, Columbia University Irving Medical Center, New York Presbyterian \\ Hospital, New York, NY, USA; ${ }^{6}$ Pathology and Laboratory Medicine Institute, Cleveland \\ Clinic, Cleveland, $\mathrm{OH}$, USA and ${ }^{7}$ Institute of Pathology, Lausanne University Hospital \\ (CHUV), Lausanne, Switzerland.
}

\section{ABSTRACT}

I ndolent T-cell lymphoproliferative disorders of the gastrointestinal tract are rare clonal T-cell diseases that more commonly occur in the intestines and have a protracted clinical course. Different immunophenotypic subsets have been described, but the molecular pathogenesis and cell of origin of these lymphocytic proliferations is poorly understood. Hence, we performed targeted next-generation sequencing and comprehensive immunophenotypic analysis of ten indolent T-cell lymphoproliferative disorders of the gastrointestinal tract, which comprised $\mathrm{CD}^{+}(\mathrm{n}=4), \mathrm{CD}^{+}$ $(\mathrm{n}=4), \mathrm{CD}^{+} / \mathrm{CD}^{+}(\mathrm{n}=1)$ and $\mathrm{CD} 4 / \mathrm{CD} 8(\mathrm{n}=1)$ cases. Genetic alterations, including recurrent mutations and novel rearrangements, were identified in $8 / 10(80 \%)$ of these lymphoproliferative disorders. The CD4 ${ }^{+}, \mathrm{CD}^{+} / \mathrm{CD}^{+}$, and CD4/CD8 cases harbored frequent alterations of JAK-STAT pathway genes $(5 / 6,82 \%)$; STAT3 mutations $(n=3)$, SOCS1 deletion $(n=1)$ and STAT3-JAK2 rearrangement $(\mathrm{n}=1)$, and $4 / 6(67 \%)$ had concomitant mutations in epigenetic modifier genes (TET2, DNMT3A, KMT2D). Conversely, $2 / 4(50 \%)$ of the CD8 $8^{+}$cases exhibited structural alterations involving the $3^{\prime}$ untranslated region of the IL 2 gene. Longitudinal genetic analysis revealed stable mutational profiles in $4 / 5(80 \%)$ cases and acquisition of mutations in one case was a harbinger of disease transformation. The $\mathrm{CD}^{+}$and $\mathrm{CD}^{+} / \mathrm{CD}^{+}$lymphoproliferative disorders displayed heterogeneous Th1 (T-bet $\left.{ }^{+}\right)$, Th2 $\left(\right.$GATA3 $\left.^{+}\right)$or hybrid Th1/Th2 $\left(\right.$T-bet $^{+} /$GATA3 $\left.^{+}\right)$profiles, while the majority of $\mathrm{CD}^{+}$disorders and the CD4/CD8 disease showed a type2 polarized (GATA3 ${ }^{+}$) effector T-cell (Tc2) phenotype. Additionally, CD103 expression was noted in $2 / 4 \mathrm{CD}^{+}$cases. Our findings provide insights into the pathogenetic bases of indolent T-cell lymphoproliferative disorders of the gastrointestinal tract and confirm the heterogeneous nature of these diseases. Detection of shared and distinct genetic alterations of the JAK-STAT pathway in certain immunophenotypic subsets warrants further mechanistic studies to determine whether therapeutic targeting of this signaling cascade is efficacious for a proportion of patients with these recalcitrant diseases.

\section{Introduction}

Non-Hodgkin lymphomas frequently occur in the gastrointestinal (GI) tract, with the majority representing B-cell neoplasms..$^{1-3} \mathrm{~T}$-cell lymphomas account for $10-20 \%$ of all primary GI lymphomas. ${ }^{1-3}$ Aggressive lymphomas, including
Ferrata Storti Foundation

Haematologica 2020

Volume 105(7):1895-1906

\section{Correspondence:}

CRAIG SODERQUIST

crs2130@cumc.columbia.edu

GOVIND BHAGAT

gb96@cumc.columbia.edu

Received: July 8, 2019.

Accepted: September 25, 2019.

Pre-published: September 26, 2019.

doi:10.3324/haematol.2019.230961

Check the online version for the most updated information on this article, online supplements, and information on authorship \& disclosures: www.haematologica.org/content/105/7/1895

(C)2020 Ferrata Storti Foundation

Material published in Haematologica is covered by copyright. All rights are reserved to the Ferrata Storti Foundation. Use of published material is allowed under the following terms and conditions:

https://creativecommons.org/licenses/by-nc/4.0/legalcode. Copies of published material are allowed for personal or internal use. Sharing published material for non-commercial purposes is subject to the following conditions:

https://creativecommons. org//icenses/by-nc/4.0/legalcode, sect. 3. Reproducing and sharing published material for commercial purposes is not allowed without permission in writing from the publisher. 
enteropathy-associated T-cell lymphoma (EATL) and monomorphic epitheliotropic intestinal T-cell lymphoma (MEITL), are among the more common types of primary GI T-cell lymphomas, which are associated with high morbidity and mortality.1,4,5 In recent years, there has been a growing awareness of indolent $\mathrm{T}$ - and natural killer (NK)-cell lymphoproliferative disorders, which can also arise within the GI tract and involve a variety of GI organs. ${ }^{67}$ The pathogenesis of indolent NK-cell disorders is unclear and it is not yet known if they constitute neoplastic proliferations of NK cells.? Indolent T-cell lymphoproliferative disorders (ITLPD) of the GI tract, which constitute an immunophenotypically diverse group of clonal T-cell diseases, have been better characterized and hence included as provisional entities in the revised $4^{\text {th }}$ edition of the World Health Organization (WHO) classification of lymphoid neoplasms. ${ }^{1}$ The clinical, morphological, and immunophenotypic features of ITLPD of the GI tract differ from those of other types of primary GI T-cell lymphomas ${ }^{6,8-16}$ and their cellular derivation, although not well established, is also considered to be distinct., ${ }^{911}$ Overlapping genomic and genetic alterations have been reported in EATL and MEITL. ${ }^{17-21}$ Limited data suggest a different spectrum of genomic aberrations in ITLPD of the GI tract, ${ }^{11,13}$ and until recently, no recurrent genetic abnormality had been identified in these disorders. ${ }^{15}$ However, the mutational landscape and molecular pathways underlying the initiation and progression of ITLPD of the GI tract are unknown and the cell of origin of the different immunophenotypic subsets has not been defined. To gain further insights into the biology of these rare diseases, we performed comprehensive immunohistochemical, molecular and targeted next-generation sequencing analyses of a series of ten cases.

\section{Methods}

\section{Case selection}

The pathology department databases of multiple institutions were searched for primary GI T-cell lymphomas, over a 23-year period (1996-2018), to identify cases fulfilling histopathological and clinical criteria of ITLPD as defined in the revised WHO classification. ${ }^{1}$ Clinical data, including therapy and outcomes, were obtained from the treating physicians or electronic medical records. The study was performed in accordance with the principles of the Declaration of Helsinki and protocols approved by the Institutional Review Boards of the participating institutions.

\section{Morphology and immunophenotypic analysis}

Hematoxylin and eosin-stained formalin-fixed, paraffin-embedded (FFPE) biopsy sections were reviewed to assess cyto-architectural features. Immunohistochemical staining was performed using a comprehensive panel of antibodies, including those directed against T-cell antigens, lineage-associated transcription factors, immune checkpoint molecules, histone modifications and cytokine signaling molecules (Online Supplementary Methods). The percentage of cells expressing nuclear T-bet and GATA3 was assessed in areas of dense lymphocytic infiltration determined by $\mathrm{CD} 4$ and $\mathrm{CD} 8$ staining. Cases with $>50 \%$ cellular staining by both markers were deemed to co-express T-bet and GATA3. For pSTAT3 and pSTAT5, $>10 \%$ nuclear staining was considered positive. Flow cytometry was performed on cell suspensions prepared from tissue samples (Online Supplementary Methods).

\section{T-cell receptor gene rearrangement analysis}

Polymerase chain reaction (PCR) analysis to determine clonal Tcell receptor beta (TRB) and/or gamma (TRG) gene rearrangement was performed using the 'Biomed-2' primers on DNA extracted from fresh or FFPE GI biopsies, lymph nodes, peripheral blood, and bone marrow mononuclear cells, as previously described..$^{22}$

\section{Next-generation sequencing}

Targeted next-generation sequencing of lesional and matched normal (control) tissue samples was performed using a custom panel of 465 cancer-associated genes, as previously described. ${ }^{23}$ Variant calling required a variant allelic fraction of at least $5 \%$ and at least ten variant reads. Variants with an allele prevalence $>0.01 \%$ in gnomAD, those reported as benign or likely benign in ClinVar, and germline variants present in the normal samples or inferred from variant allelic fractions were excluded from the analysis. Non-synonymous variants that were not known driver mutations were analyzed by PolyPhen-2, SIFT, REVEL, and MetaSVM algorithms. Copy number changes were determined based on read depths using fragments per kilobase per million mapped reads ${ }^{24}$ normalized to a pool of sex-matched control samples. The Fusion and Chromosomal Translocation Enumeration and Recovery Algorithm (FACTERA $)^{25}$ was used to detect structural chromosomal alterations, which were confirmed by PCR using breakpoint-specific primers and Sanger sequencing of the PCR products (Online Supplementary Methods).

\section{Fluorescent in-situ hybridization analysis}

Fluorescent in-situ hybridization (FISH) analysis was performed to assess for SETD2 and JAK2 alterations on FFPE tissue sections using custom designed hybridization probes and dual-color breakapart probes (Oxford Gene Technologies Inc, Tarrytown, NY, USA), respectively, as previously described. ${ }^{17,26}$ Hybridization patterns of at least 100 tumor nuclei were reviewed for each probe. Cases were considered to have SETD2 deletion if the percentage of nuclei with SETD2 locus deletion exceeded the cut-off value of $11.2 \%$, and JAK2 rearrangement if the frequency of split-signals exceeded the cut-off value of $5.0 \%$.

\section{Results}

\section{Clinical characteristics and patients' outcomes}

Ten patients (male:female $=8: 2$ ) with ITLPD of the GI tract were identified at the contributing centers (cases 1, 2, and 4 were reported previously). ${ }^{11}$ The clinical features are summarized in Table 1. The median age at diagnosis was 45 years (range, 37-64 years). The ethnicity of eight patients for whom this information was available was: White $(\mathrm{n}=5)$, Hispanic $(\mathrm{n}=2)$, and Asian $(\mathrm{n}=1)$. The most common signs and symptoms were diarrhea $(70 \%)$, weight loss $(60 \%)$, and abdominal pain (50\%), with durations ranging from 2 to 16 years prior to diagnosis. Two patients lacked GI symptoms, with disease detected incidentally during routine colonoscopy and workup for inguinal lymphadenopathy. One patient had peptic ulcer disease, $H$. pylori infection and was serologically positive for hepatitis B and C viruses (case 9) and one patient (case 10) had a history of Crohn disease. Eight patients had been previously misdiagnosed as having celiac disease, seronegative and refractory to a gluten-free diet, and/or other types of lymphomas. The endoscopic findings included mucosal nodularity $(70 \%)$, scalloping ( $40 \%)$, erythema $(40 \%)$, decreased duodenal folds $(30 \%)$, and polyps $(20 \%)$. Common radiographic findings included abdomi- 
nal lymphadenopathy (55\%), bowel wall thickening $(33 \%)$, and dilated bowel loops (33\%). Biopsy-proven sites of disease included the small intestine $(90 \%)$, colon $(60 \%)$, stomach (40\%), bone marrow $(30 \%$, one case only had cytogenetic evidence of disease), and inguinal lymph nodes $(20 \%)$. Seven of nine $(77 \%)$ patients received therapeutic interventions consisting of steroids and/or chemotherapy; two were monitored expectantly. Six of

Table 1. Clinical characteristics of patients with gastrointestinal indolent T-cell lymphoproliferative disorders.

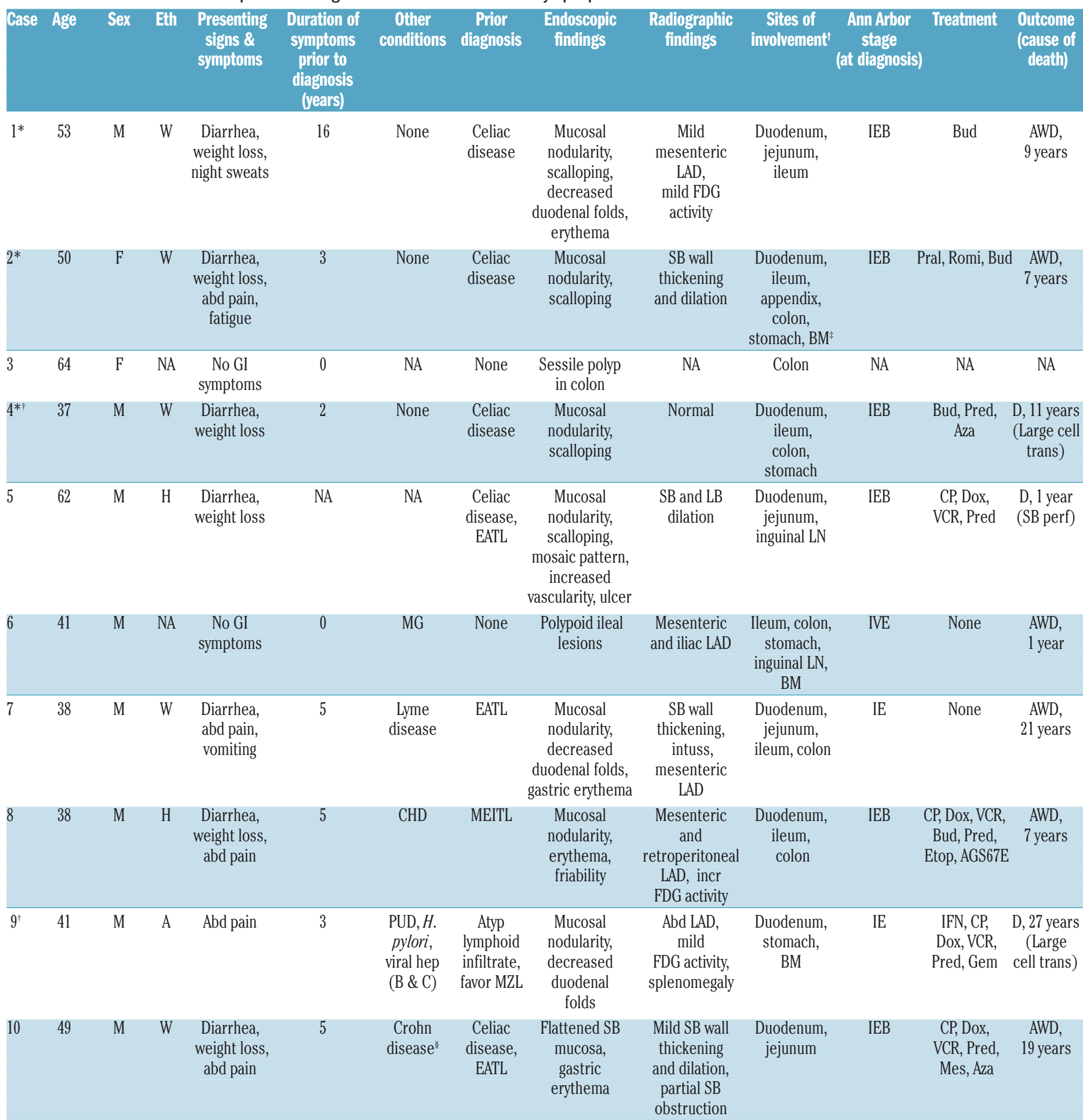

A: Asian; abd: abdominal; AGS67E: anti-CD37 monoclonal antibody AGS67E; AWD: alive with disease; Aza: azathioprine; BM: bone marrow; Bud: budesonide; CHD: congenital heart disease; CP: cyclophosphamide; D: dead; Dox: doxorubicin; EATL: enteropathy associated T-cell lymphoma; Eth: ethnicity; Etop: etoposide; F: female; FDG: fluorodeoxyglucose; Gem: gemcitabine; GI: gastrointestinal; H: Hispanic; hep: hepatitis; IFN: interferon; incr: increased; intuss: intussusception; LAD: lymphadenopathy; LB: large bowel; LN: lymph node; M: male; MEITL: monomorphic epitheliotropic intestinal T-cell lymphoma; Mes: mesalamine; MG: monoclonal gammopathy; MZL: marginal zone lymphoma; NA: not available; perf: perforation; PUD: peptic ulcer disease; Pral: pralatrexate; Pred:

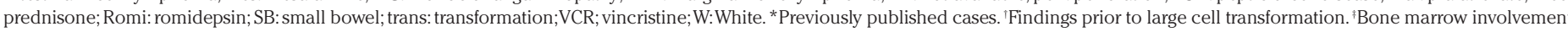
was detected by cytogenetic analysis; there was no morphological or immunophenotypic evidence of disease and TCR $\beta$ polyclonal chain reaction showed polyclonal products. ${ }^{\circledR}$ Biopsies diagnosed as Crohn disease were not reviewed by authors. 
nine $(66 \%)$ patients are alive with persistent disease and three (33\%) have died; one (case 5) due to septicemia and multiorgan failure following chemotherapy-induced intestinal perforation 1 year after diagnosis and two (cases 4 and 9) due to disease transformation 11 and 27 years after diagnosis.

\section{Morphological features}

All cases with involvement of the small intestines displayed a dense diffuse or nodular infiltrate of small-sized lymphocytes in the lamina propria (Figures $1 \mathrm{~A}$ and $2 \mathrm{~A}$ ), with extension into the submucosa noted in a subset. Villous atrophy was observed in three of the nine cases of ITLPD (cases 2, 4, 9) (Figure 1B), however the villi were expanded (blunted appearance) (Figure 2B) in many cases, and all except one (case 10) showed crypt hyperplasia. The lymphocytes had round, ovoid or mildly irregular nuclei, variable fine or coarse chromatin, indistinct or small nucleoli, and scant or moderate cytoplasm (Figures $1 \mathrm{C}$ and $2 \mathrm{C}$ ). No significant increase in intraepithelial lymphocytes was identified (Figures $1 \mathrm{~B}$ and $2 \mathrm{~B}$ ), although focal lymphocytic infiltration of the epithelium was present in four of nine cases of ITLPD (cases 1, 2, 4, and 7). Scattered lymphoid aggregates were seen in all except one
ITLPD (case 5). Sparse, patchy mucosal infiltrates were noted in the seven cases with gastric and/or colonic involvement. Mitotic figures and apoptotic cells were inconspicuous. No angiocentricity, angiodestruction, ulceration, or necrosis was observed. The histopathological findings of the small intestinal biopsy from one patient with large cell transformation, available for review (case 4), were reported previously.

\section{Immunophenotypic features}

The immunophenotypic profiles of all cases are summarized in Table 2. Four of ten (40\%) ITLPD were CD4+ (Figure 1D), four (40\%) were $\mathrm{CD}^{+}$(Figure 2D) and one each $(10 \%)$ was $\mathrm{CD}^{+} / \mathrm{CD}^{+}$("double-positive") and CD4/CD8 ("double-negative"). All cases analyzed expressed CD2 (Figure 1E) and CD3 (Figures 1F and 2E). Other T-cell antigens were expressed by the majority (Figure 1G, H); variable downregulation or loss of CD5 and/or CD7 was seen in four of ten cases $\left(2 / 4 \mathrm{CD}^{+}, 1 / 4\right.$ $\mathrm{CD}^{+}$, and $1 / 1$ double-negative). All except one $\mathrm{CD}^{+}$ case and the CD4/CD8 case displayed a cytotoxic immunophenotype, with TIA-1 expression (Figure 2F) noted in three of four cases and variable granzyme $\mathrm{B}$ expression (Figure 2G) observed in two of four CD8 ${ }^{+}$
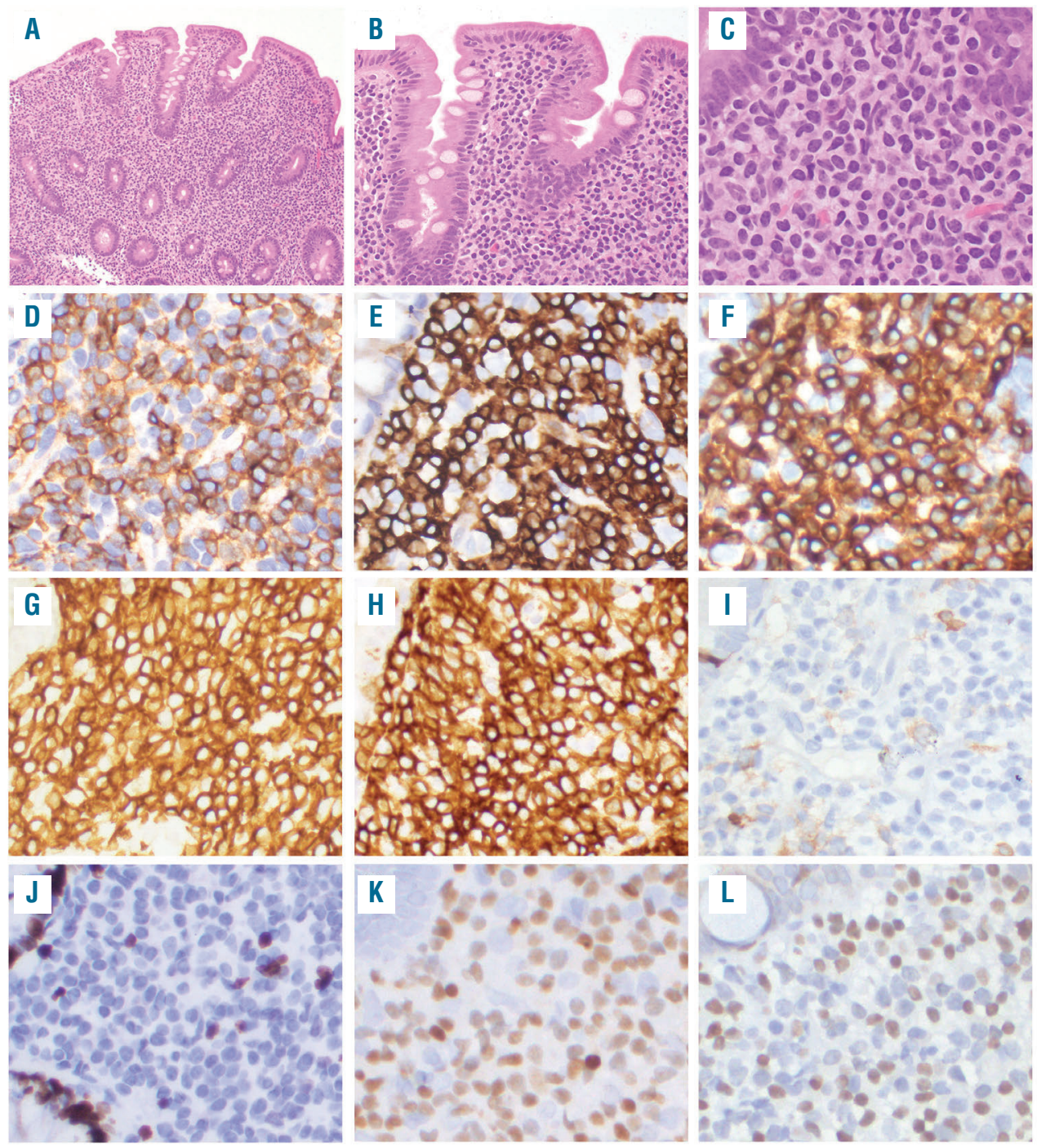

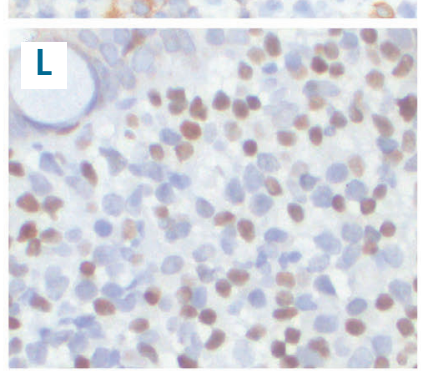

Figure 1. Morphological and immunophenotypic features of $\mathrm{CD}^{+}$indolent T-cell lymphoproliferative disorders of the gastrointestinal tract. (A) A duodenal biopsy (case 2) shows a dense lymphocytic infiltrate within the lamina propria, as well as villous atrophy and crypt hyperplasia. (B) There is no increase in intraepithelial lymphocytes. (C) The lymphocytes are small and have round to ovoid nuclei, fine chromatin, indistinct or small nucleoli, and moderate pale pink cytoplasm. The lymphocytes express (D) CD4, (E) CD2, (F) CD3, (G) CD5, and (H) CD7. (I) The neoplastic cells do not express CD103. (J) The $\mathrm{Ki}-67$ proliferation index is low $(<5 \%)$. The majority of cells are (K) $\mathrm{T}_{\text {-bet }}{ }^{+}$, however, $50 \%$ also express (L) GATA3. 
cases and in the CD4/CD8 case. CD103 expression was detected in two of four $\mathrm{CD}^{+}$cases (Figure $2 \mathrm{H}$ ), with one also showing partial CD56 expression (case 8) (Figure 2I). The $\mathrm{CD}^{+} / \mathrm{CD}^{+}$and the $\mathrm{CD} 4 / \mathrm{CD} 8$ cases expressed $\mathrm{PD}-$ 1. CD20 highlighted mucosal lymphoid follicles, but the neoplastic cells were CD20 in all ITLPD. Surface TCR $\alpha \beta$ expression was observed in all cases evaluated by flow cytometry and none expressed TCR $\gamma \delta$. All analyzed cases were negative for BCL6, CD10, FoxP3, MATK, PDL1 or CD30, however CD30 expression (and acquisition of cytotoxic proteins) was observed, and previously reported, upon large cell transformation (case 4). ${ }^{11}$ The Ki-67 proliferation index was low $(<5 \%)$ in all ITLPD evaluated (Figures 1J and 2J).

\section{Determination of the cell of origin}

Since a good correlation between the transcriptional profiles and immunohistochemistry for T-bet and GATA3 has been reported in T-cell lymphomas, ${ }^{27}$ we assessed Tbet and GATA3 expression by immunohistochemistry to determine the cell of origin of ITLPD (Table 2, Online Supplementary Table S1, Online Supplementary Figure S1). The $\mathrm{CD}^{+}$cases showed heterogeneity with regards to $\mathrm{T}$ - bet and GATA3 expression: one case each was $\mathrm{T}^{-}$-bet ${ }^{+}$and GATA $^{+}$, suggesting T-helper type 1 (Th1) and type 2 (Th2) lineage, respectively and two cases showed T-bet and GATA3 co-expression - hybrid Th1/Th2 profile (Figure $1 \mathrm{~K}, \mathrm{~L}$ ). The $\mathrm{CD}^{+} / \mathrm{CD}^{+}$ITLPD also co-expressed T-bet and GATA3. The CD4/CD8 case and three of the four $(75 \%) \mathrm{CD}^{+}$cases were GATA3 ${ }^{+}$, implying a type-2polarized effector T-cell (Tc2) phenotype and one CD8 case showed T-bet and GATA3 co-expression (Figure 2K, L). Sequential analysis of one $\mathrm{CD}^{+}$ITLPD (case 2) showed a shift from a Th1/Th2 (T-bet and GATA3 coexpression) to Th2 (GATA3) phenotype over the course of disease. Double staining for T-bet and GATA3, performed in a subset (cases 2,7, and 8), confirmed distinct T-bet and GATA3 $^{+}$as well as T-bet and GATA3 co-expressing lymphocytes (data not shown).

\section{T-cell receptor gene rearrangement analysis}

Clonal $T R B$ and/or TRG rearrangement products were detected in all ITLPD. In patients in whom longitudinal testing was performed, similar sized peaks were observed in all samples, confirming persistence of the same lymphocytic clone.
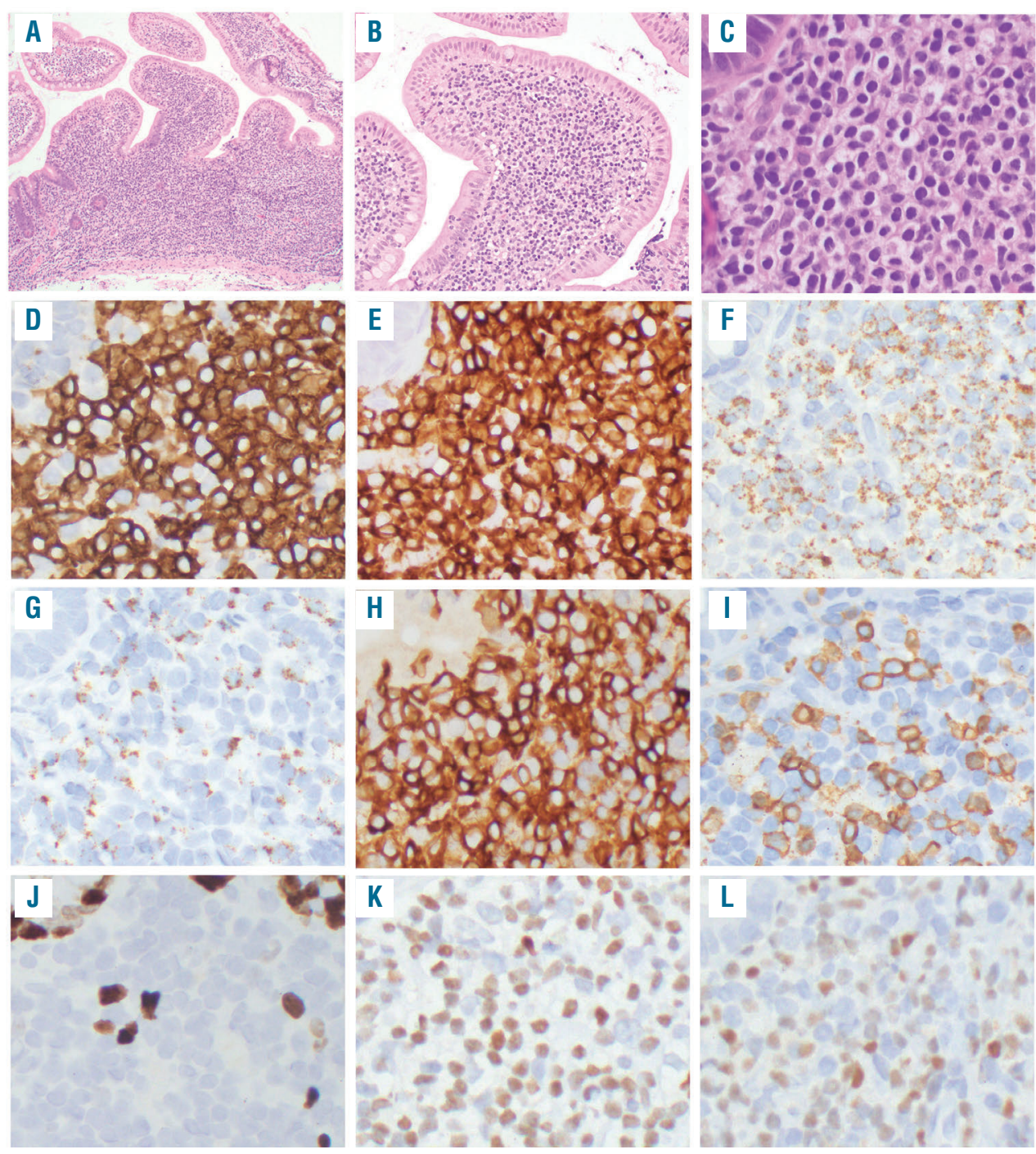

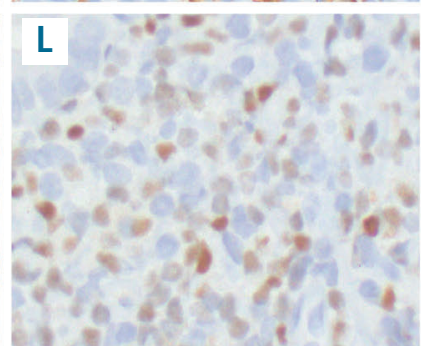

Figure 2. Morphological and immunophenotypic features of $\mathrm{CD8}^{+}$indolent T-cell lymphoproliferative disorders of the gastrointestinal tract. (A) An ileal biopsy (case 8) shows a dense mucosal lymphocytic infiltrate expanding the lamina propria and widening the villi; no villous atrophy is present but the crypts are hyperplastic. (B) Small clusters of lymphocytes are seen within the villus epithelium along the lateral edges. There is no increase in intraepithelia lymphocytes. (C) The lymphocytes are small and have round or oval nuclei, condensed chromatin, indistinct nucleoli, and scant to moderate clear or pale pink cytoplasm. The lymphocytes express (D) CD8 and (E) CD3. Most of the cells express the cytotoxic marker (F) TIA1 and (G) granzyme $B$ is expressed by a subset. $(\mathrm{H})$ The lymphocytes are $\mathrm{CD} 103^{+}$and a subset expresses (I) CD56. (J) The $\mathrm{Ki}-67$ proliferation index is low $(<5 \%)$. The majority of cells express (K) GATA3, but $60 \%$ also show (L) T-bet expression. 


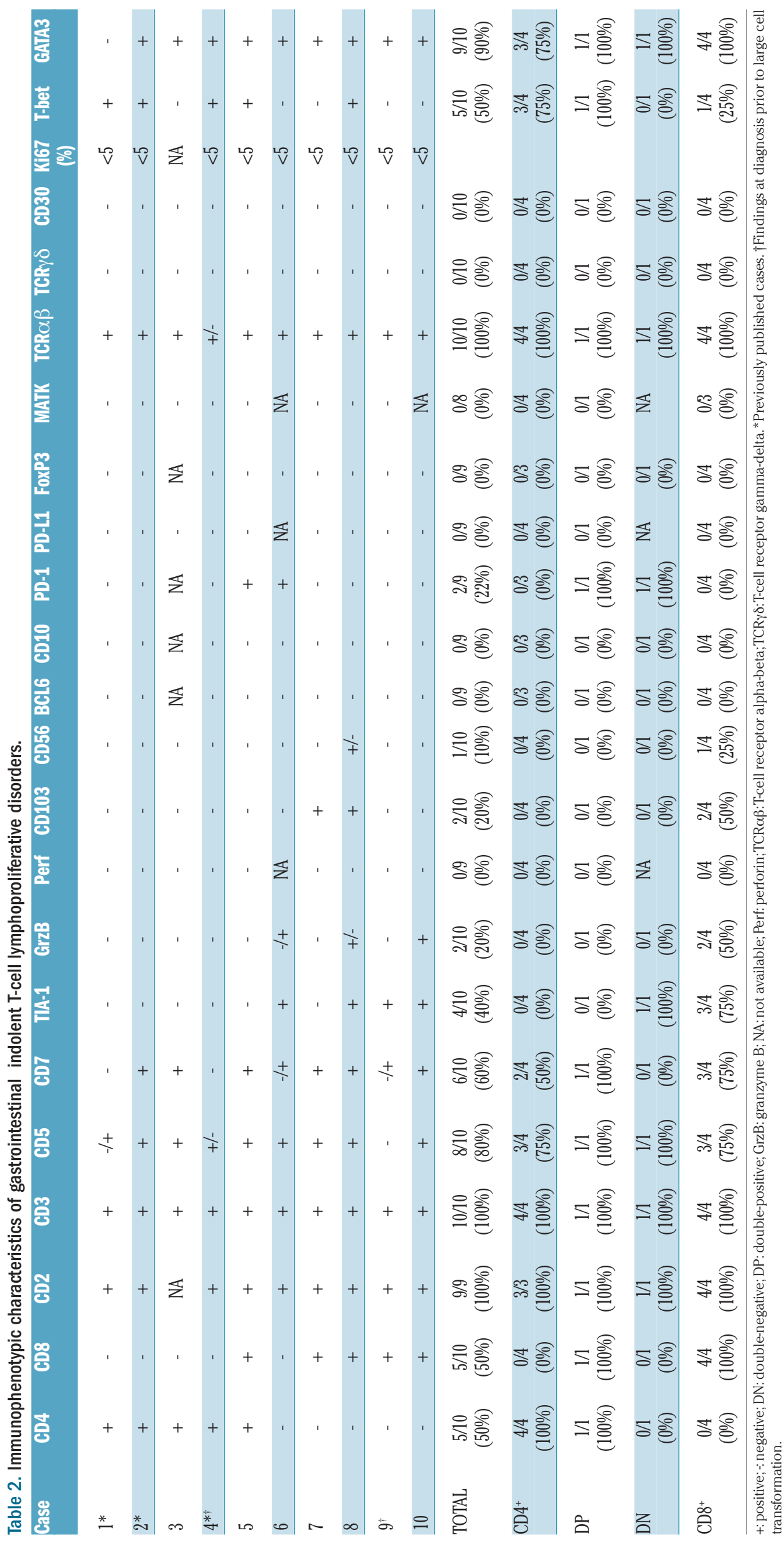




\section{Next-generation sequencing analysis}

Targeted sequencing of 20 ITLPD biopsies from ten patients and seven matched normal samples (cases 1, 2, 4, 7-10) revealed 36 genetic variants, including 29 nonsynonymous single nucleotide variants, one small indel, and six structural variants. The average on-target coverage was 1059x (range 809x - 1639x). Twenty-three of the 36 alterations were predicted to be pathogenic based on the published literature or prediction algorithms; the remaining 13 mutations were classified as variants of uncertain significance (Online Supplementary Table S2).

The genetic alterations and their expected functional consequences are summarized in Table 3. Pathogenic or potentially pathogenic changes were identified in eight of ten $(80 \%)$ ITLPD. Three of four $(75 \%) \mathrm{CD}^{+}$cases and the $\mathrm{CD}^{+} / \mathrm{CD}^{+}$and $\mathrm{CD} 4 / \mathrm{CD} 8$ cases harbored alterations of JAK-STAT signaling pathway genes. STAT3 SH2 domain hotspot mutations (D661Y and S614R) were noted in three cases and one case each had a SOCS1 deletion and a STAT3-JAK2 rearrangement. Of note, conventional cytogenetic analysis had previously revealed a balanced translocation $\mathrm{t}(9 ; 17)(\mathrm{p} 24 ; \mathrm{q} 21)$ in the latter case, the breakpoints corresponding to the JAK2 and STAT3 loci, and JAK2 rearrangement was confirmed by FISH analysis. Concomitant mutations in epigenetic modifier genes (TET2, DNMT3A, and KMT2D) were observed in four

Table 3. Genetic alterations in gastrointestinal indolent T-cell lymphoproliferative disorders.

\begin{tabular}{|c|c|c|c|c|}
\hline Case & Phenotype & $\begin{array}{l}\text { Time point } \\
\text { (years following diagnosis) }\end{array}$ & Genetic alterations & Predicted functional consequence \\
\hline \multirow[t]{2}{*}{1} & \multirow[t]{2}{*}{$\mathrm{CD}^{+}$} & 2.5 & $\begin{array}{l}\text { STAT3 (c.1981G>T, p. D661Y) } \\
\text { TET2 (c.2457T>G, p. Y819*) }\end{array}$ & $\begin{array}{l}\text { Activation of JAK-STAT pathway } \\
\text { Altered DNA methylation }\end{array}$ \\
\hline & & 7.9 & $\begin{array}{l}\text { STAT3 (c.1981G>T, p. D661Y) } \\
\text { TET2 (c.2457T>G, p. Y819*) }\end{array}$ & $\begin{array}{l}\text { Activation of JAK-STAT pathway } \\
\text { Altered DNA methylation }\end{array}$ \\
\hline \multirow[t]{3}{*}{2} & \multirow[t]{3}{*}{$\mathrm{CD}^{+}$} & 0 & $\begin{array}{l}\text { STAT3-JAK2 rearrangement } \\
\text { TNFAIP3 (c.857T>G, p.L286*) }\end{array}$ & $\begin{array}{l}\text { Activation of JAK-STAT pathway } \\
\text { Activation of NF-אB pathway }\end{array}$ \\
\hline & & 2.2 & $\begin{array}{l}\text { STAT3-JAK2 rearrangement } \\
\text { TNFAIP3 (c.857T >G, p.L286*) }\end{array}$ & $\begin{array}{l}\text { Activation of JAK-STAT pathway } \\
\text { Activation of NF-אB pathway }\end{array}$ \\
\hline & & 6.4 & $\begin{array}{l}\text { STAT3-JAK2 rearrangement } \\
\text { TNFAIP3 (c.857T>G, p.L286*) }\end{array}$ & $\begin{array}{l}\text { Activation of JAK-STAT pathway } \\
\text { Activation of NF-кB pathway }\end{array}$ \\
\hline 3 & $\mathrm{CD}^{+}$ & 0 & SOCS1 deletion & Activation of JAK-STAT pathway \\
\hline \multirow[t]{4}{*}{4} & \multirow[t]{4}{*}{$\mathrm{CD}^{+}$} & 0.5 & KMT2D (c.13105_13108del, p.L4369fs) & Altered histone modification \\
\hline & & 7.4 & $\begin{array}{c}\text { KMT2D (c.13105_13108del, p.L4369fs) } \\
\text { DIS3 (c.1115T>C, p.L372P) }\end{array}$ & $\begin{array}{l}\text { Altered histone modification } \\
\text { Altered RNA processing and decay }\end{array}$ \\
\hline & & 11.5 & $\begin{array}{c}\text { KMT2D (c.13105_13108del, p.L4369fs) } \\
\text { DIS3 (c.1115T>C, p.L372P) } \\
\text { MAPK1 (c.965A>T, p.E322V) } \\
\text { TP53 (c.743G>A, p.R248Q) } \\
\text { POLE (c.4090C >T, p.R1364C) }\end{array}$ & $\begin{array}{l}\text { Altered histone modification } \\
\text { Altered RNA processing and decay } \\
\text { Activation of RAS-RAF-MAPK pathway } \\
\text { DNA repair/cell cycle dysregulation } \\
\text { Altered DNA repair and replication }\end{array}$ \\
\hline & & $11.7 \dagger$ & $\begin{array}{c}\text { KMT2D (c.13105_13108del, p.L4369fs) } \\
\text { DIS3 (c.1115T>C, p.L372P) } \\
\text { MAPK1 (c.965A>T, p.E322V) } \\
\text { TP53 (c.743G>A, p.R248Q) } \\
\text { POLE (c.4090C>T, p.R1364C) } \\
\text { TET2 (c.2725C>T, p.Q909*) } \\
\text { SMAD4 (c.404G>A, p.R135Q) } \\
\text { SF3B1 (c.2584G>A, p.E862K) }\end{array}$ & $\begin{array}{l}\text { Altered histone modification } \\
\text { Altered RNA processing and decay } \\
\text { Activation of RAS-RAF-MAPK pathway } \\
\text { DNA repair/ cell cycle dysregulation } \\
\text { Altered DNA repair and replication } \\
\text { Altered DNA methylation } \\
\text { Activation of TGF- } \beta \text { pathway } \\
\text { Altered RNA splicing }\end{array}$ \\
\hline 5 & $\mathrm{CD} 4^{+} / \mathrm{CD} 8^{+}$ & 0 & $\begin{array}{c}\text { STAT3 (c.1842C>G, p.S614R) } \\
\text { DNMT3A (c.2116G>T, p.G706W) } \\
\text { CDKN2A (c.322G>A, p.D108N) }\end{array}$ & $\begin{array}{l}\text { Activation of JAK-STAT pathway } \\
\text { Altered DNA methylation } \\
\text { Cell cycle checkpoint (G1-to-S) } \\
\text { dysregulation }\end{array}$ \\
\hline 6 & $\mathrm{CD} 4 / \mathrm{CD} 8$ & 0 & $\begin{array}{l}\text { STAT3 (c.1840A>C, p.S614R) } \\
\text { KMT2D (c.9415C>G, p.P3139A) }\end{array}$ & $\begin{array}{l}\text { Activation of JAK-STAT pathway } \\
\text { Altered histone modification }\end{array}$ \\
\hline \multirow[t]{3}{*}{7} & \multirow[t]{3}{*}{$\mathrm{CD}^{+}$} & 0 & IL2-RHOH rearrangement ${ }^{*}$ & Unknown \\
\hline & & 3.9 & IL2-RHOH rearrangement ${ }^{\ddagger}$ & Unknown \\
\hline & & 6.1 & IL2-RHOH rearrangement ${ }^{*}$ & Unknown \\
\hline \multirow[t]{3}{*}{8} & \multirow[t]{3}{*}{$\mathrm{CD}^{+}$} & 0 & $\begin{array}{c}\text { IL2 3' UTR deletion", IL2-TNIP3 rearrangement } \\
\text { MCM5 (c.2080A>T, p.I694F) }\end{array}$ & $\begin{array}{l}\text { Unknown } \\
\text { Cell cycle dysregulation }\end{array}$ \\
\hline & & 4.3 & $\begin{array}{l}\text { IL2 3' UTR deletion }{ }^{\ddagger}, \text { IL2-TNIP3 rearrangement } \\
\text { MCM5 (c.2080A }>\text { T, p.I694F) }\end{array}$ & $\begin{array}{c}\text { Unknown } \\
\text { Cell cycle dysregulation }\end{array}$ \\
\hline & & 6.4 & $\begin{array}{l}\text { IL2 3' UTR deletion, IL2-TNIP3 rearrangement } \\
\text { MCM5 (c.2080A>T, p.I694F) }\end{array}$ & $\begin{array}{l}\text { Unknown } \\
\text { Cell cycle dysregulation }\end{array}$ \\
\hline 9 & $\mathrm{CD}^{+}$ & 14 & None identified & NA \\
\hline 10 & $\mathrm{CD}^{+}+$ & 10.8 & None identified & $\mathrm{NA}$ \\
\hline
\end{tabular}

NA: not applicable. 'Large cell transformation. ${ }^{\star}$ Confirmed by breakpoint-specific polymerase chain reaction and Sanger sequencing. 
cases. A missense mutation in the cell cycle regulatory gene CDKN2A and a nonsense mutation in TNFAIP 3 were detected in one case each.

Two of the CD8 ${ }^{+}$ITLPD exhibited structural chromosome alterations involving the interleukin-2 (IL2) gene. One case demonstrated an IL2-RHOH (Ras homolog family member $\mathrm{H}$ ) rearrangement, representing an inversion of chromosome 4, with breakpoints occurring in the 3' untranslated region (3' UTR) of both IL2 (chr4:123372863, c. ${ }^{* 44)}$ (Figure 3A) and $\mathrm{RHOH} \mathrm{(chr4:40246032,} \mathrm{c.}{ }^{* 449}$ ) genes. This rearrangement did not affect the coding sequence, but resulted in the deletion of a portion of the $3^{\prime}$ UTR of IL2, including five of the six AU-rich regulatory elements (ARE, AUUUA). The "reciprocal" RHOH-IL2 rearrangement had breakpoints in the 3' UTR of $R H O H$ (chr4:40246006, c.*424) and intron 3 of IL2 (chr4:123373085, c.352-67). Another $\mathrm{CD}^{+}$case demonstrated a $1.2 \mathrm{Mb}$ deletion on chromosome $4 \mathrm{q}$, beginning 5 base pairs downstream of the IL2 stop codon (chr4:123372903, c.*5) (Figure 3D) and ending 6 kilobases upstream of the TNFAIP3 interacting protein 3 (TNIP3) gene (chr4:122154953), deleting all regulatory elements from the IL2 3' UTR. In addition, an inversion, with breakpoints in exon 4 of IL2 (chr4:123372912, c.457) and intron 2 of TNIP3 (chr4:122128556, c.89+9014) was identified (Figure 3D). A missense mutation in the minichromosome maintenance complex component 5 (MCM5) gene was also identified in this case. The chromosome breakpoints were confirmed in all ITLPD samples with structural IL2 alterations via PCR amplification and Sanger sequencing

A

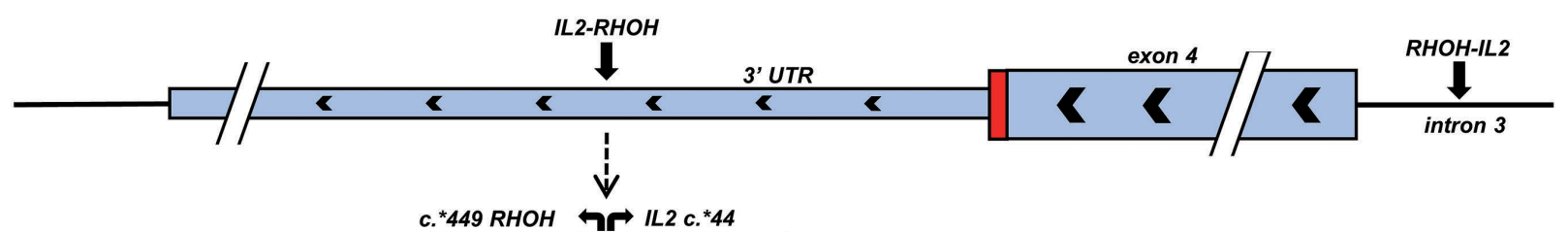

B

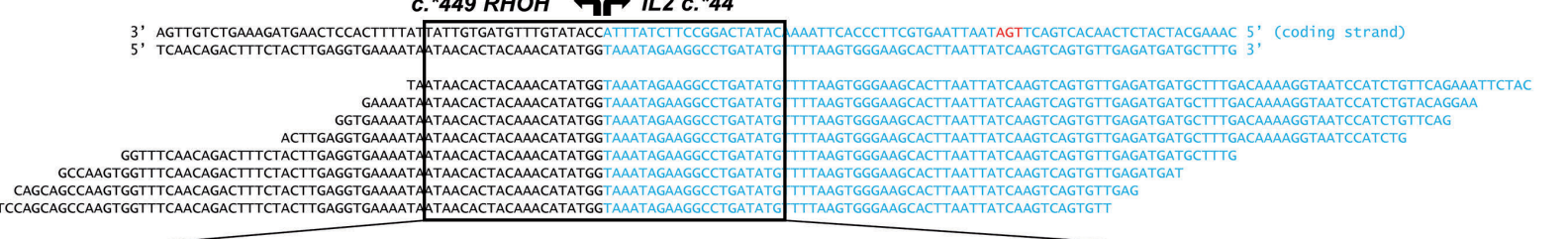

C

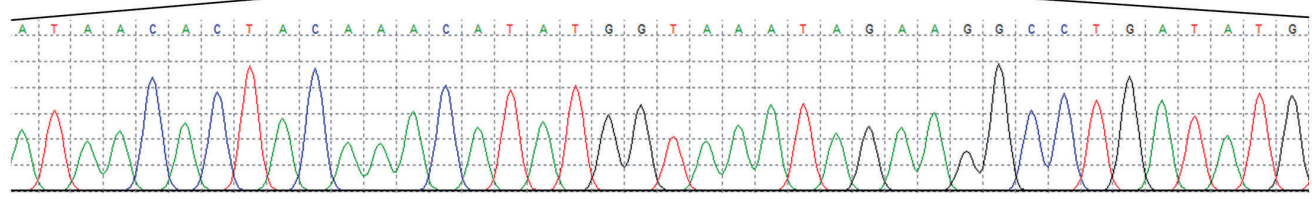

D

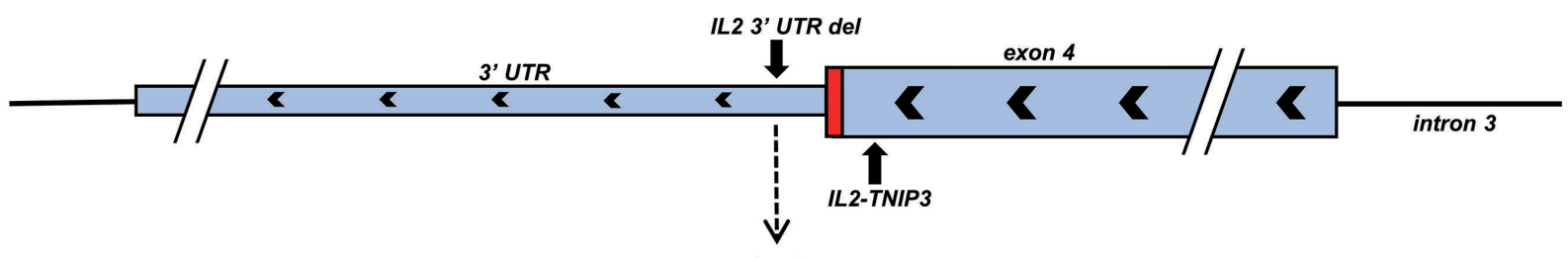

E

chr4:122154953+ $\rightarrow$ IL2 c.*5

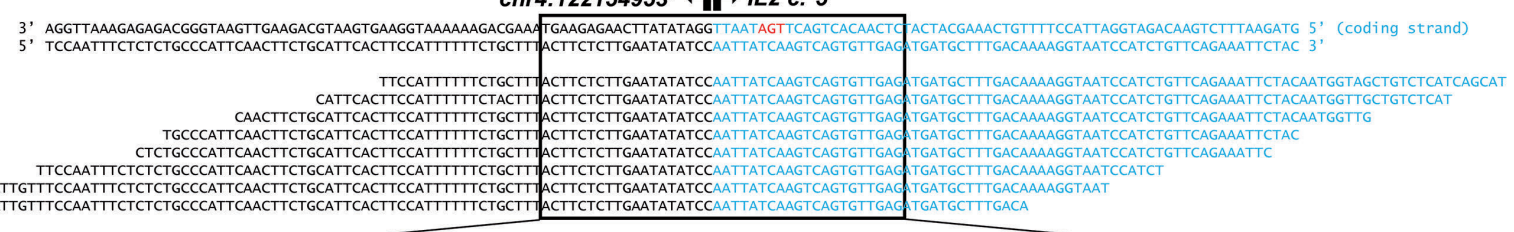

$\mathrm{F}$

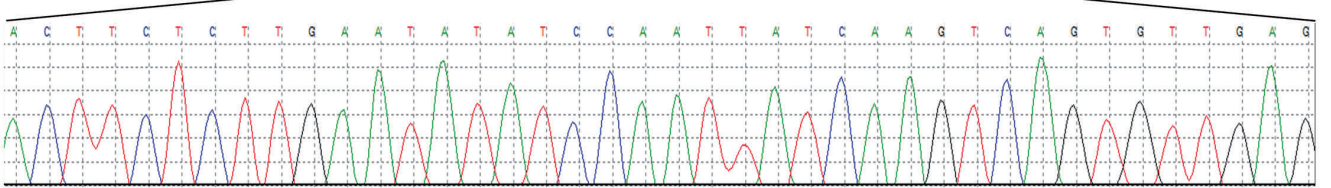

Figure 3. Structural chromosome alterations of the IL2 gene in CD8 ${ }^{+}$indolent T-cell lymphoproliferative disorders. In case 7 , (A) two chromosome breaks were detected as a consequence of a rearrangement involving the 3' untranslated region (UTR) of IL2 and 3' UTR of RHOH ("IL2-RHOH") and a reciprocal rearrangement involving intron 3 of IL2 and the 3' UTR of $\mathrm{RHOH}$ ("RHOH-IL2"). (B) Pile-up of a subset of reads mapping to the IL2-RHOH rearrangement. (C) Sanger sequencing validation of the fusion breakpoints. In case 8, (D) two chromosome breaks were observed due to a 1.2 Mb deletion spanning the majority of the 3 ' UTR of IL2 and a portion of the intergenic region between IL2 and TNIP3 (“IL2 3' UTR del") and an inversion involving exon 4 of IL2 and intron 2 of TNIP3 (“IL2-TNIP3"). (E) Pile-up of a subset of reads mapping to the IL2 3' UTR deletion. (F) Sanger sequencing validation of the deletion breakpoints. ${ }^{\dagger}$ Chromosome position based on assembly GRCh37.p13. 
(Figure 3B, C, E, F). No pathogenic mutations or structural abnormalities were observed in two $\mathrm{CD}^{+}$ITLPD (cases 9 and 10), although a variant of uncertain significance was observed in one case (Online Supplementary Table S2).

Longitudinal analysis of five ITLPD (cases 1, 2, 4, 7, 8) revealed stable mutational profiles in four ITLPD. Accrual of mutations over time was noted in one CD4 ${ }^{+}$ITLPD (case 4). Only a KMT2D frameshift mutation was detected in the first biopsy, obtained shortly after diagnosis. Additional mutations were identified at later time points, including a missense TP53 mutation prior to disease transformation. Of interest, biopsies at the first, second, and fourth time-points had shown different chromosome copy number changes (reported previously), ${ }^{11}$ but none of the altered regions corresponded to the loci of mutated genes.

\section{Evaluation of the SETD2-H3K36me3 axis}

No SETD2 mutations were observed by next-generation sequencing analysis and FISH did not detect any SETD2 deletions in the cases analyzed. Additionally, no loss of SETD2 protein or H3K36me3 was detected by immunohistochemistry and $\mathrm{H} 3 \mathrm{~K} 36 \mathrm{me} 2$ expression was observed in all analyzed cases (Figure 4A-C, Online Supplementary Table S3).

\section{Evaluation of JAK-STAT pathway activation}

Due to the presence of frequent and recurrent genetic alterations targeting the JAK-STAT pathway and IL2 genes, we evaluated pSTAT3-Y705 and pSTAT5-Y694 expression by immunohistochemistry to assess activation of the JAK-STAT signaling pathway. All nine tested cases only showed single scattered or small clusters of nuclear pSTAT3-Y705 and pSTAT5-Y694 positive cells (<10\%) in all biopsies (Figure 4E, F, Online Supplementary Table S3).

\section{Discussion}

Despite an increasing awareness of ITLPD of the GI tract, deciphering their molecular pathogenesis and cellular origins has been challenging, in part due to the rarity of these disorders. In this study, comprising one of the largest series of cases evaluated, we delineate novel genetic alterations, including recurrent mutations and rearrangements, suggest cellular origins, and expand the immunophenotypic spectrum of these diseases.

The clinical presentations and disease course of our patients were largely congruent with previous descriptions. ${ }^{6,-16}$ Of interest, the ITLPD were detected incidentally in two asymptomatic patients, which has rarely been documented. ${ }^{10}$ A history of Crohn disease has been reported in some patients with CD8 ${ }^{+}$ITLPD,,$^{12,13}$ which was also the case for one patient in our series. Prior erroneous diagnoses of seronegative, refractory celiac disease in a high proportion $(50 \%)$ of patients were deemed to be the consequence of misinterpretation of the histopathological changes and incomplete laboratory testing. Due to the relatively recent recognition of these disorders, it is not surprising that $40 \%$ of the ITLPD in the current study had been previously misdiagnosed as aggressive intestinal $\mathrm{T}$ cell lymphomas (EATL and MEITL). Extra-GI disease was observed more frequently $(40 \%)$ in our series than in previously reported series, and transformation to aggressive lymphoma, which is considered rare, $, 111,15,28$ occurred in two patients, including one with a $\mathrm{CD}^{+}$ITLPD. These findings emphasize the need for comprehensive clinical and laboratory evaluation and long-term follow-up of individuals with these disorders.

Next-generation sequencing of the ITLPD revealed genetic alterations in $80 \%$ of the cases, including mutations in JAK-STAT signaling pathway genes, observed in
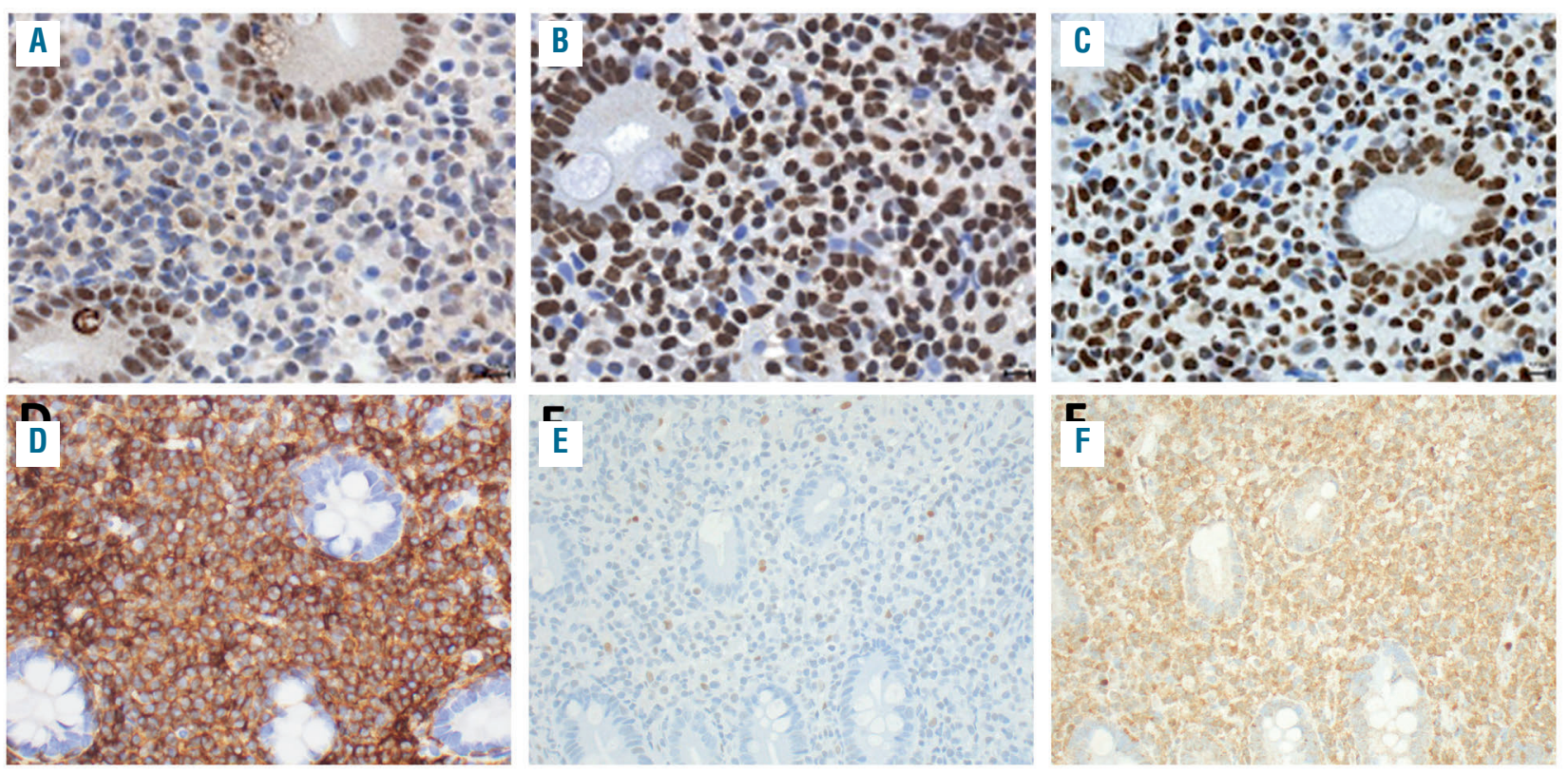

Figure 4. Analysis of the SETD2-H3K36me3 axis and JAK-STAT pathway activation. Immunohistochemical analysis of a CD4+ indolent T-cell lymphoproliferative disorder with STAT3-JAK2 rearrangement (case 2) shows preserved (A) SETD2, (B) H3K36me2, and (C) H3K36me3 protein expression. The lymphocytes express (D) CD4. Only a few scattered (E) pSTAT3-Y705 ${ }^{+}$and (F) PSTAT5-Y694 ${ }^{+}$cells are noted (comprising $<10 \%$ of the neoplastic lymphocytes). 
$75 \%$ of the $\mathrm{CD}_{4}^{+}$cases and in the $\mathrm{CD} 4^{+} / \mathrm{CD} 8^{+}$and $\mathrm{CD} 4$ /CD8 cases. The STAT3 D661Y and S614R mutations are well-characterized hotspot mutations that impart greater hydrophobicity to the SH2 dimerization surface and promote STAT3 nuclear localization and activation. ${ }^{29}$ These mutations have been described in a myriad of lymphoid neoplasms and are quite frequent in T-large granular lymphocytic leukemia. ${ }^{29}$ Perry et al. did not detect STAT3 $\mathrm{SH} 2$ domain hotspot mutations in five cases analyzed by Sanger sequencing, although all tested cases were CD $8{ }^{+12}$ Deletion of SOCS1, a negative regulator of the JAK family proteins ${ }^{30}$ which was seen in a colonic $\mathrm{CD} 4^{+}$ ITLPD, is a recurrent abnormality in a variety of T-cell lymphomas and more commonly reported in mycosis fungoides. ${ }^{31}$ We confirm that STAT3-JAK2 rearrangement is a recurrent event in $\mathrm{CD}_{4}^{+}$ITLPD although this alteration was only observed in one $(25 \%)$ of our cases compared to four of five $(80 \%)$ cases in the series reported by Sharma et al. ${ }^{15}$

Loss-of-function mutations in epigenetic modifier genes (TET2, DNMT3A, KMT2D) represented the next most commonly altered gene class, identified in $40 \%$ of cases and restricted to $\mathrm{CD} 4^{+}, \mathrm{CD} 4^{+} / \mathrm{CD} 8^{+}$, and $\mathrm{CD} 4 / \mathrm{CD} 8$ cases. Mutations in epigenetic modifiers, which are believed to be early events in lymphomagenesis ${ }^{32,33}$ and known to cooperate with other mutations in fostering neoplastic transformation, ${ }^{33,34}$ have also been reported in diverse $\mathrm{T}$ cell malignancies. ${ }^{33,35}$ However, in contrast to other T-cell lymphomas, ${ }^{36} \mathrm{IDH} 1 / 2$ mutations were not observed in any ITLPD. Although not recurrent, mutations in CDKN2A and TNFAIP3 suggest roles of cell cycle deregulation ${ }^{37}$ and NF- $\mathrm{KB}$ activation ${ }^{38}$ in the pathogenesis of at least some ITLPD.

Structural chromosome alterations recurrently targeting the 3' UTR of the IL2 gene, which were identified in $50 \%$ of the CD8+ ITLPD, have not been described before. The rearrangements and deletions led to the loss of most or all of the regulatory ARE involved in mRNA stability. Studies in mitogen-stimulated Jurkat cells have shown that deletion of these regulatory elements, which act as binding sites for components of the mRNA degradation machinery, ${ }^{39}$ results in a longer half-life of IL2 mRNA. ${ }^{40}$ Whether these alterations lead to changes in the cellular localization of the IL2 transcript or affect the assembly or composition of protein complexes that modulate activities beyond its 3' UTR-independent functions has not been investigated. An IL2-TNFRSF17 rearrangement, ${ }^{41}$ resulting from $\mathrm{t}(4 ; 16)(\mathrm{q} 26 ; \mathrm{p} 13),{ }^{41}$ was previously reported in a $\mathrm{CD}^{+}$ ITLPD. ${ }^{9}$ However, in contrast to our cases, the breakpoints in that case mapped to intron 3 of IL 2 and exon 1 of the Bcell maturation antigen (BCMA) gene, also known as tumor necrosis factor receptor superfamily member 17 (TNFRSF17). ${ }^{41}$ The authors detected chimeric IL2TNFRSF17 mRNA, but no fusion protein was identified. The functional significance of the prior and current IL2 genetic alterations remains unknown.

Despite the frequent JAK-STAT pathway gene mutations and structural alteration of the IL2 gene, which encodes a key T-cell cytokine that signals via the JAKSTAT pathway, ${ }^{42}$ none of the ITLPD analyzed showed high-level pSTAT3 or pSTAT5 expression. Our findings are similar to those of Perry et al. who also did not observe significant pSTAT3 expression, ${ }^{12}$ but contrast with those of Sharma et al. who reported pSTAT5 expression in three of four cases with STAT3-JAK2 rearrangements. ${ }^{15}$ The rea- sons for these discrepant findings are unclear. It is plausible that the mutations simply augment the sensitivity of ITLPD to cytokine stimulation, enhancing ligand-mediated signaling as described in other T-cell lymphomas, ${ }^{43}$ and aberrant proliferations of intraepithelial lymphocytes in refractory celiac disease type $2^{44}$ that harbor STAT3 mutations.

On analysis of serial samples, acquisition of additional mutations, including those targeting genes involved in the DNA damage response (TP53, POLE) were only identified in an ITLPD that transformed to aggressive lymphoma. It is possible that ineffective DNA repair mechanisms fueled acquisition of additional mutations and complex chromosome changes in this case. ${ }^{11}$ It is unclear if prolonged azathioprine therapy played a role in genomic evolution. Nonetheless, this and other cases in our series as well as those published previously highlight the futility of genotoxic chemotherapeutic agents for treating ITLPD of the GI tract. The prognostic relevance of periodic genetic analysis needs to be assessed in future larger studies.

Our findings indicate that ITLPD of the GI tract share certain pathogenic mechanisms with other intestinal Tcell lymphomas. As in our cohort, mutations in JAK-STAT pathway genes represent the most frequent alterations in EATL, MEITL, and intestinal T-cell lymphoma, not otherwise specified. ${ }^{17-21}$ Similarly, loss-of-function mutations in epigenetic modifier genes and DNA damage repair genes have also been reported in aggressive intestinal T-cell lymphomas. ${ }^{17,18}$ In contrast to EATL and MEITL, however, SETD2 mutations or deletions were not seen in any ITLPD and the burden of pathogenic alterations in ITLPD appears lower..$^{17,18}$

ITLPD of the GI tract are immunophenotypically heterogeneous diseases. Our study revealed a few unique features that are worth highlighting. In addition to $\mathrm{CD} 4^{+}$ $\mathrm{CD}^{+}$, and $\mathrm{CD} 4 / \mathrm{CD} 8$ ITLPD, we describe a $\mathrm{CD}^{+} / \mathrm{CD} 8^{+}$ (double-positive) case. Two ITLPD with a similar phenotype were recently reported from the USA and China. ${ }^{15,45}$ Two of our CD8+ ITLPD expressed CD103, which has not been documented before. Prior sporadic cases of $\mathrm{CD}_{103}{ }^{+}$ITLPD have all been of CD4 T-cell lineage..$^{10,13}$ These ITLPD could arise from $\alpha \mathrm{E}$ integrin-expressing lamina propria $\mathrm{T}$ cells, ${ }^{46}$ but the possibility of activationinduced upregulation of CD103 cannot be excluded. 47,48 Of note, one $\mathrm{CD}_{103^{+}} \mathrm{CD}^{+}$ITLPD also showed focal CD56 expression. Distinguishing such cases from MEITL can be challenging; however, in addition to the clinical presentation and course, the presence of small lymphocytes with bland cytomorphology confined to the lamina propria, absent MATK expression, and a low Ki-67 index, can help establish a diagnosis of ITLPD. Evaluation of SETD2 and H3K36me3 expression can also aid in differentiating ITLPD from MEITL, which frequently show loss of SETD2 and H3K36 trimethylation. ${ }^{17}$

ITLPD of the GI tract are thought to originate from mucosal $T$ cells, but the cell of origin of different disease subsets has not been clarified. Absence of FoxP3 and Tfollicular helper (TFH) cell markers in the current and previously reported $\mathrm{CD}^{+}$ITLPD $^{11,16}$ argues against their derivation from regulatory $\mathrm{T}$ cells or TFH cells. Based on expression of T-bet and GATA3, which are transcription factors regulating $\mathrm{CD} 4^{+}$Th1 vs. Th2 cell fate decisions, the $\mathrm{CD}^{+}$and $\mathrm{CD} 4^{+} / \mathrm{CD}^{+}$ITLPD in our series displayed Th1, Th2, or hybrid Th1/2 profiles. It is not known whether ITLPD with the latter profile develop directly 
from naïve $T$ cells into bifunctional mucosal Th1/2 cells, similar to those described in primary immune responses against parasites, which help dampen inflammation, ${ }^{49}$ or derive from Th1 or Th2 cells that have undergone cytokine-mediated reprogramming to acquire a Th1/Th2 phenotype, with concomitant production of Th1 and Th2 cytokines. ${ }^{50}$ The phenotypic shift from a Th1/Th2 to Th2 profile over time, observed in one $\mathrm{CD} 4^{+}$case, suggests lineage (and possibly functional) plasticity of at least a subset of ITLPD. The majority of the $\mathrm{CD} 8^{+}$cases and the CD4/CD8 ITLPD displayed a Tc2 phenotype. ${ }^{51}$ Besides orchestrating diverse functions in $\mathrm{CD}^{+}$T-helper cells, GATA3 also regulates the activation, homeostasis, and cytolytic activity of $\mathrm{CD} 8^{+} \mathrm{T}$ cells. ${ }^{52}$ The significance of $\mathrm{T}$ bet/GATA3 co-expression in CD8 $8^{+}$ITLPD is unknown. It must be pointed out that despite the reported concordance between the transcriptional and protein expression profiles of T-bet and GATA3 in certain T-cell lymphomas,$^{27}$ the definitive lineage (and function) of neoplastic $T$ cells cannot be ascertained based on the expression of single lineage-associated transcription factors. Cytokine profiling and in vitro functional studies are awaited for confirmation of our observations. Contrary to observations in peripheral T-cell lymphoma, not otherwise specified, ${ }^{27,53,54}$ however, an inferior prognostic impact of GATA3 expression was not apparent in our series of ITLPD.

In conclusion, our study reveals considerable immunophenotypic and genetic heterogeneity of GI ITLPD. We describe recurrent and novel genetic abnormalities in different immunophenotypic subtypes of GI ITLPD which implicate deregulated cytokine signaling and epigenetic alterations in disease pathogenesis. It is hoped that future unbiased interrogation of ITLPD genomes and transcriptomes as well as mechanistic studies will help to clarify the cell of origin and the functional consequences of the underlying genetic aberrations in these rare disorders, opening the door for targeted, less toxic and more effective therapies.

\section{Acknowledgments}

We would like to thank Raymond Yeh, PhD, for designing the primers, analyzing Sanger sequencing results, and generating electropherogram images of the IL2 rearrangements.

\section{References}

1. Swerdlow S, Campo E, Harris N, et al., editors. World Health Organization Classification of Tumours of Haematopoietic and Lymphoid Tissues. Lyon, France: IARC; 2016.

2. Foukas PG, de Leval L. Recent advances in intestinal lymphomas. Histopathology. 2015;66(1):112-136.

3. Wu XC, Andrews P, Chen VW, Groves FD. Incidence of extranodal non-Hodgkin lymphomas among whites, blacks, and Asians/Pacific Islanders in the United States: anatomic site and histology differences. Cancer Epidemiol. 2009;33(5):337346.

4. Delabie J, Holte H, Vose JM, et al. Enteropathy-associated T-cell lymphoma: clinical and histological findings from the International Peripheral T-Cell Lymphoma Project. Blood. 2011;118(1):148-156.

5. Tan SY, Chuang SS, Tang T, et al. Type II EATL (epitheliotropic intestinal T-cell lymphoma): a neoplasm of intra-epithelial Tcells with predominant CD8 $\alpha \alpha$ phenotype. Leukemia. 2013;27(8):1688-1696.

6. Matnani R, Ganapathi KA, Lewis SK, Green PH, Alobeid B, Bhagat G. Indolent Tand NK-cell lymphoproliferative disorders of the gastrointestinal tract: a review and update. Hematol Oncol. 2017:35(1):3-16.

7. Xia D, Morgan EA, Berger D, Pinkus GS, Ferry JA, Zukerberg LR. NK-cell enteropathy and similar indolent lymphoproliferative disorders. Am J Clin Pathol. 2018; 151(1):75-85

8. Carbonnel F, D'Almagne H, Lavergne A, et al. The clinicopathological features of extensive small intestinal CD4 T cell infiltration. Gut. 1999;45(5):662-667.

9. Carbonnel F, Lavergne A, Messing B, et al. Extensive small intestinal T-cell lymphoma of low-grade malignancy associated with a new chromosomal translocation. Cancer. 1994;73(4):1286-1291.

10. Hirakawa K, Fuchigami T, Nakamura S, et al. Primary gastrointestinal T-cell lymphoma resembling multiple lymphomatous polyposis. Gastroenterology. 1996;111(3): 778-782

11. Margolskee E, Jobanputra V, Lewis SK, Alobeid B, Green PH, Bhagat G. Indolent small intestinal CD4+ T-cell lymphoma is a distinct entity with unique biologic and clinical features. PLoS One. 2013;8(7): e68343.

12. Perry AM, Warnke RA, Hu $\mathrm{O}$, et al. Indolent $\mathrm{T}$-cell lymphoproliferative disease of the gastrointestinal tract. Blood. 2013;122(22):3599-3606.

13. Malamut G, Meresse B, Kaltenbach S, et al Small intestinal CD4+ T-cell lymphoma is a heterogenous entity with common pathology features. Clin Gastroenterol Hepatol. 2014;12(4):599-608.

14. Edison N, Belhanes-Peled H, Eitan Y, et al. Indolent T-cell lymphoproliferative disease of the gastrointestinal tract after treatment with adalimumab in resistant Crohn's colitis. Hum Pathol. 2016;57:45-50

15. Sharma A, Oishi N, Boddicker RL, et al. Recurrent STAT3-JAK2 fusions in indolent T-cell lymphoproliferative disorder of the gastrointestinal tract. Blood. 2018;131(20) 2262-2266.

16. Sena Teixeira Mendes L, Attygalle AD, Cunningham D, et al. CD4-positive small $\mathrm{T}$-cell lymphoma of the intestine presenting with severe bile-acid malabsorption: a supportive symptom control approach. Br J Haematol. 2014:167(2):265-269.

17. Roberti A, Dobay MP, Bisig B, et al. Type II enteropathy-associated T-cell lymphoma features a unique genomic profile with highly recurrent SETD2 alterations. Nat Commun. 2016;(7):12602.

18. Moffitt $A B$, Ondrejka SL, McKinney M, et al. Enteropathy-associated $\mathrm{T}$ cell lymphoma subtypes are characterized by loss of function of SETD2. J Exp Med. 2017;214(5):1371-1386.

19. Nairismägi ML, Tan J, Lim JQ, et al. JAKSTAT and G-protein-coupled receptor sig- naling pathways are frequently altered in epitheliotropic intestinal T-cell lymphoma. Leukemia. 2016;30(6):1311-1319.

20. Küçük C, Jiang B, Hu X, et al. Activating mutations of STAT5B and STAT3 in lymphomas derived from $\gamma \delta$-T or NK cells. Nat Commun. 2015;(6):6025.

21. Nicolae A, Xi L, Pham TH, et al. Mutations in the JAK/STAT and RAS signaling pathways are common in intestinal T-cell lymphomas. Leukemia. 2016;30(11):2245-2247.

22. van Dongen JJM, Langerak AW, Brüggemann $M$, et al. Design and standardization of PCR primers and protocols for detection of clonal immunoglobulin and $\mathrm{T}$ cell receptor gene recombinations in suspect lymphoproliferations: report of the BIOMED-2 Concerted Action BMH4 CT98-3936. Leukemia. 2003;17(12):22572317

23. Margolskee E, Jobanputra V, Jain P, et al. Genetic landscape of T- and NK-cell posttransplant lymphoproliferative disorders. Oncotarget. 2016;7(25):37636-37648.

24. Trapnell C, Williams BA, Pertea G, et al Transcript assembly and quantification by RNA-Seq reveals unannotated transcripts and isoform switching during cell differentiation. Nat Biotechnol. 2010;28(5):511515.

25. Newman AM, Bratman S V., Stehr H, et al. FACTERA: a practical method for the discovery of genomic rearrangements at breakpoint resolution. Bioinformatics. 2014;30(23):3390-3393

26. Tang G, Sydney Sir Philip JK, Weinberg O et al. Hematopoietic neoplasms with 9p24/JAK2 rearrangement: a multicenter study. Mod Pathol 2019;32(4):490-498.

27. Iqbal J, Wright G, Wang C, et al. Gene expression signatures delineate biologic and prognostic subgroups in peripheral Tcell lymphoma. Blood. 2014;123(19):2915 2924.

28. Perry AM, Bailey NG, Bonnett M, Jaffe ES, Chan WC. Disease progression in a patient with indolent $\mathrm{T}$-cell lymphoproliferative 
disease of the gastrointestinal tract. Int J Surg Pathol. 2019;27(1):102-107.

29. Koskela HLM, Eldfors S, Ellonen P, et al. Somatic STAT3 mutations in large granular lymphocytic leukemia. N Engl J Med. 2012;366(20):1905-1913

30. Liau NPD, Laktyushin A, Lucet IS, et al. The molecular basis of JAK/STAT inhibition by SOCS1. Nat Commun. 2018;9 (1):1558.

31. Bastidas Torres AN, Cats D, Mei H, et al. Genomic analysis reveals recurrent deletion of JAK-STAT signaling inhibitors HNRNPK and SOCS1 in mycosis fungoides. Genes Chromosom Cancer. 2018;57(12):653-664.

32. Schwartz FH, Cai $\mathrm{Q}$, Fellmann E, et al. TET2 mutations in B cells of patients affected by angioimmunoblastic T-cell lymphoma. J Pathol. 2017;242(2):129-133.

33. Van Arnam JS, Lim MS, Elenitoba-Johnson KSJ. Novel insights into the pathogenesis of T-cell lymphomas. Blood. 2018;131(21): 2320-2330.

34. Zang S, Li J, Yang H, et al. Mutations in 5methylcytosine oxidase TET2 and RhoA cooperatively disrupt $\mathrm{T}$ cell homeostasis. J Clin Invest. 2017;127(8):2998-3012.

35. Watatani Y, Sato Y, Miyoshi H, et al. Molecular heterogeneity in peripheral $\mathrm{T}$ cell lymphoma, not otherwise specified revealed by comprehensive genetic profiling. Leukemia. 2019;33(12):2867-2883.

36. Cairns RA, Iqbal J, Lemonnier F, et al. IDH2 mutations are frequent in angioimmunoblastic T-cell lymphoma. Blood. 2012;119(8):1901-1903.

37. Foulkes WD, Flanders TY, Pollock PM, Hayward NK. The CDKN2A (p16) gene and human cancer. Mol Med. 1997;3(1):520.

38. Wenzl K, Manske MK, Sarangi V, et al. Loss of TNFAIP3 enhances MYD88L265P-driven signaling in non-Hodgkin lymphoma. Blood Cancer J. 2018;8(10):97.

39. Myer VE, Fan XC, Steitz JA. Identification of $\mathrm{HuR}$ as a protein implicated in AUUUAmediated mRNA decay. EMBO J. 1997;16(8):2130-2139.

40. Chen CY, Del Gatto-Konczak F, Wu Z, Karin M. Stabilization of interleukin-2 mRNA by the c-Jun NH2-terminal kinase pathway. Science. 1998;280(5371):19451949.

41. Laâbi Y, Gras MP, Carbonnel F et al. A new gene, BCM, on chromosome 16 is fused to the interleukin 2 gene by a $\mathrm{t}(4 ; 16)(\mathrm{q} 26 ; \mathrm{p} 13)$ translocation in a malignant $\mathrm{T}$ cell lymphoma. EMBO J. 1992;11(11):3897-3904.

42. Ross SH, Cantrell DA. Signaling and function of interleukin-2 in T lymphocytes. Annu Rev Immunol. 2018;36(1):411-433.

43. Chen J, Zhang Y, Petrus MN, et al. Cytokine receptor signaling is required for the survival of ALK- anaplastic large cell lymphoma, even in the presence of JAK1/STAT3 mutations. Proc Natl Acad Sci U S A. 2017;114(15):3975-3980.

44. Ettersperger J, Montcuquet N, Malamut G, et al. Interleukin-15-dependent T-cell-like innate intraepithelial lymphocytes develop in the intestine and transform into lymphomas in celiac disease. Immunity. 2016;45(3):610-625.

45. Guo L, Wen Z, Su X, Xiao S, Wang Y. Indolent $\mathrm{T}$-cell lymphoproliferative disease with synchronous diffuse large B-cell lymphoma. Medicine (Baltimore). 2019;98(17): e15323.

46. Farstad IN, Halstensen TS, Lien B, Kilshaw PJ, Lazarovitz AI, Brandtzaeg P. Distribution of $\beta 7$ integrins in human intes- tinal mucosa and organized gut-associated lymphoid tissue. Immunology. 1996;89(2): 227-237.

47. Micklem KJ, Dong Y, Willis A, et al. HML1 antigen on mucosa-associated $T$ cells, activated cells, and hairy leukemic cells is a new integrin containing the beta 7 subunit. Am J Pathol. 1991;139(6):1297-301.

48. Shaw SK, Brenner MB. The beta 7 integrins in mucosal homing and retention. Semin Immunol. 1995;7(5):335-342.

49. Peine M, Rausch S, Helmstetter C, et al Stable T-bet+GATA-3+ Th1/Th2 hybrid cells arise in vivo, can develop directly from naive precursors, and limit immunopathologic inflammation. PLoS Biol. 2013;11 (8):e1001633

50. Hegazy AN, Peine M, Helmstetter C, et al. Interferons direct Th2 cell reprogramming to generate a stable GATA-3+T-bet+ cell subset with combined Th2 and Th1 cell functions. Immunity. 2010;32(1):116-128.

51. Fox A, Harland KL, Kedzierska K, Kelso A. Exposure of human CD8+ T cells to type-2 cytokines impairs division and differentiation and induces limited polarization. Front Immunol. 2018;9:1141.

52. Tai TS, Pai SY, Ho IC. GATA-3 Regulates the homeostasis and activation of CD8+ T cells. J Immunol. 2013;190(1):428-437.

53. Wang T, Feldman AL, Wada DA et al GATA-3 expression identifies a high-risk subset of PTCL, NOS with distinct molecular and clinical features. Blood. 2014;123 (19):3007-3015

54. Manso R, Bellas C, Martín-Acosta P, et al C-MYC is related to GATA3 expression and associated with poor prognosis in nodal peripheral T-cell lymphomas. Haematologica. 2016;101(8):e336-338. 